DE

M E D I C I N A

T R O P I C A L

$\mathrm{DE}$

SÃO PAULO

JOURNAL OF THE SÃO PAULO INSTITUTE OF TROPICAL MEDICINE

${ }^{1}$ Fundação Oswaldo Cruz, Instituto Oswaldo Cruz, Laboratório de Fisiologia e Controle de Artrópodes Vetores, Rio de Janeiro, Rio de Janeiro, Brazil

${ }^{2}$ Instituto de Biologia do Exército, Laboratório de Entomologia, Rio de Janeiro, Rio de Janeiro, Brazil

Correspondence to: Luciana dos Santos Dias

Fundação Oswaldo Cruz, Instituto Oswaldo Cruz, Avenida Brasil 4365, CEP 21040-360, Manguinhos, Rio de Janeiro, RJ, Brazil

E-mail: lucianad@ioc.fiocruz.br

Received: 21 March 2018

Accepted: 23 May 2018

\section{Artificial blood feeding for Culicidae colony maintenance in laboratories: does the blood source condition matter?}

Luciana dos Santos Dias ${ }^{1,2}$, Luíz Guilherme Soares da Rocha Bauzer ${ }^{1,2}$, José Bento Pereira Lima ${ }^{1,2}$

\section{ABSTRACT}

Culicidae colonization in laboratory is paramount to conduct studies aiming at a better understanding of mosquitoes' capacity to transmit pathogens that cause deadly diseases. Colonization requires female blood feeding, a necessary step for maturation of female's oocytes. Direct blood feeding on anesthetized mammals implies in a number of disadvantages when compared to artificial blood feeding. Consequently, laboratories worldwide have been trying to -feed female mosquitoes artificially in order to replace direct feeding. In this study, we compared the effects of direct blood feeding and artificial blood feeding on important life traits of three Culicidae species. Artificial feeding was performed using citrated or defibrinated sheep blood and citrated or defibrinated rabbit blood. Direct feeding was performed using anesthetized guinea pigs as the blood source and the experiment control. Results indicated that artificial feeding using sheep blood was not good enough to justify its use in the maintenance of laboratory colonies of Culicidae. However, artificial feeding using rabbit blood maintained a recovery rate always very close to the control, especially when blood was citrated. We concluded that artificial feeding using citrated rabbit blood can substitute direct feeding on mammals reducing the use of animals, eliminating the need to maintain a bioterium in the laboratory and reducing costs in scientific researches involving Culicidae vectors.

KEYWORDS: Culicidae. Colonization. Artificial blood feeding. Anticoagulants. Animal welfare

\section{INTRODUCTION}

Culicidae females, in general, need to perform hematophagy for the maturation of their oocytes ${ }^{1,2}$. The ability of hematophagous mosquitoes to transmit pathogens during blood feeding is a major public health problem ${ }^{3}$. Development and behavior studies of these insect vectors in the laboratory are important since they may expand the understanding of the vector parasite interaction and provide grounds for the direction of control measures. Therefore, colonization and maintenance of mosquitoes under controlled laboratory conditions are essential ${ }^{2}$.

The use of direct blood feeding on anesthetized mammals in the laboratory implies in a number of disadvantages, such as maintenance of a bioterium, need for a comfortable physical area for the animals and specialized personnel to manage these resources ${ }^{4-6}$. In this sense, methods for artificial blood feeding of mosquitoes have been developed aiming to abolish the direct blood feeding on mammals. These methods were developed to meet the needs of specific laboratories, considering their structure conditions and available resources. The 
methods differ in several aspects such as nature/material of the membrane lining the artificial feeding apparatus, heat source, origin of blood and anticoagulant used ${ }^{7-18}$. In common, they all take into account the three Rs principles: replacement, reduction and refinement, related to animal welfare ${ }^{19}$.

The present study aimed at determining the efficacy of artificial blood feeding on three Culicidae species: Aedes aegypti (Linnaeus, 1762), Culex quinquefasciatus (Say, 1823) and Anopheles aquasalis (Curry, 1932). This study has also investigated the possibility of maintaining Culicidae colonies in the laboratory by replacing direct feeding on mammals with artificial feeding, which is simple, cheap and easily reproducible.

\section{MATERIALS E METHODS}

\section{Rearing of mosquitoes}

The mosquito source was colonies maintained at the Laboratory of Physiology and Control of Arthropod Vectors of the Oswaldo Cruz Institute, Rio de Janeiro, RJ, Brazil (LAFICAVE - IOC / Fiocruz). In order to assure egg production and, consequently, colony perpetuation, mosquitoes have been fed directly on blood of anesthetized guinea pigs (Cavia porcellus - Linnaeus, 1758), in this laboratory.

Ae. aegypti (Rockefeller lineage) and $C x$. quinquefasciatus eggs were hatched and approximately 1,000 larvae of each species were kept in plastic bowls $(33 \times 24 \times 8 \mathrm{~cm})$ containing one liter of dechlorinated water and kept in an incubator under controlled conditions $\left(26 \pm 1{ }^{\circ} \mathrm{C}\right.$ and photoperiod light: Dark 12: 12 h). Every three days, one gram of shredded cat food (Friskies, Purina, Camaqua / RS) was provided until the larvae reached L4 stage. For An. aquasalis, eggs were hatched and 960 larvae were kept in an insectary under standard conditions $\left(27 \pm 2{ }^{\circ} \mathrm{C}\right.$ and photoperiod light: Dark 12: $12 \mathrm{~h}$ ). Larvae were reared in twelve plastic bowls containing $600 \mathrm{~mL}$ dechlorinated water and $0.2 \%$ sodium chloride solution. Approximately 80 larvae were added in each plastic bowl. All obtained larvae were fed using daily pulverized fish food $\left(\right.$ Tetramin $\left.{ }^{\circledR}\right)$. For all three species, pupae were daily transferred to $50 \mathrm{~mL}$ disposable plastic cups filled with water and placed inside cylindrical cardboard cages, measuring $16.5 \mathrm{~cm}$ in diameter by $17.5 \mathrm{~cm}$ in height, where the adults emerged. Adult cages were kept in an insectary under standard conditions $\left(26 \pm 1{ }^{\circ} \mathrm{C}, 70 \pm 10 \%\right.$ relative humidity and photoperiod light, Dark 12: $12 \mathrm{~h}$ ). Male and female adults were fed with $10 \%$ sugar solution until one day before blood feeding.

\section{Blood source for artificial feeding experiments}

Sheep and rabbit blood were obtained from the Institute of Science and Technology in Biomodels at Fiocruz (ICTB- Fiocruz). The anticoagulant sodium citrate was added to the blood, in the proportion of 1:10, in order to get a citrated blood. Defibrinated blood was obtained mechanically using 4-cm glass beads added to the blood flask, which was shaken for a few seconds. Blood flasks remained refrigerated at $4{ }^{\circ} \mathrm{C}$ until the moment of feeding. The obtained blood was used for a maximum of five days after collection.

\section{Artificial blood feeding}

Blood meal was offered to Ae. aegypti and $C x$. quinquefasciatus three days after adults emergence. For An. aquasalis, blood meal was offered five days after adults emergence. This is because this species copulates through the formation of swarms in nature what makes the copulation inside the cages not as efficient as it is for the other two species. Hence, two extra days were given to increase the chances of mating success.

The LAFICAVE colony of $C x$. quinquefasciatusis maintained in an insectary with inverted photoperiod of $12 \mathrm{~h}$. Hence, both direct blood feeding guinea pig and artificial blood feeding were carried out in dark conditions for this species. For the other two Culicidae species, blood feeding was carried out in light conditions.

For each experimental condition, two cages containing 50 females each were used. In addition, two cages whose females were fed directly in guinea pigs were used as controls. Guinea pigs were used according to the protocol approved by the Ethical Committee for the Use of Animals of the Oswaldo Cruz Foundation (CEUA - Fiocruz), a procedure already established in the laboratory. In all cases, $24 \mathrm{~h}$ prior to blood delivery, flasks containing $10 \%$ sugar solution were removed from the cages. Artificial blood feeding was performed according to the technique described by Rutledge et al. ${ }^{8}$ and Gerberg ${ }^{20}$ using a circulating water bath (VWR Scientific ${ }^{\circledR}$, model 1136). Warm water (approximately $37{ }^{\circ} \mathrm{C}$ ) circulated through thin hoses connected to jacketed glass cones with a small opening at the top and a large concave base (Figure 1).

The base aperture was occluded by a $5 \times 5 \mathrm{~cm}$ piece of Parafilm-M $\mathrm{M}^{\circledR}$ stretched until reaching $15 \times 15 \mathrm{~cm}$, which coated the entire aperture, mimicking the skin of an animal (Figure 2). Five milliliters of blood were added in the narrow top aperture so that the entire inner surface of the occluded base was covered with blood. By the time the circulating water bath was turned on, the warmed water moved through 

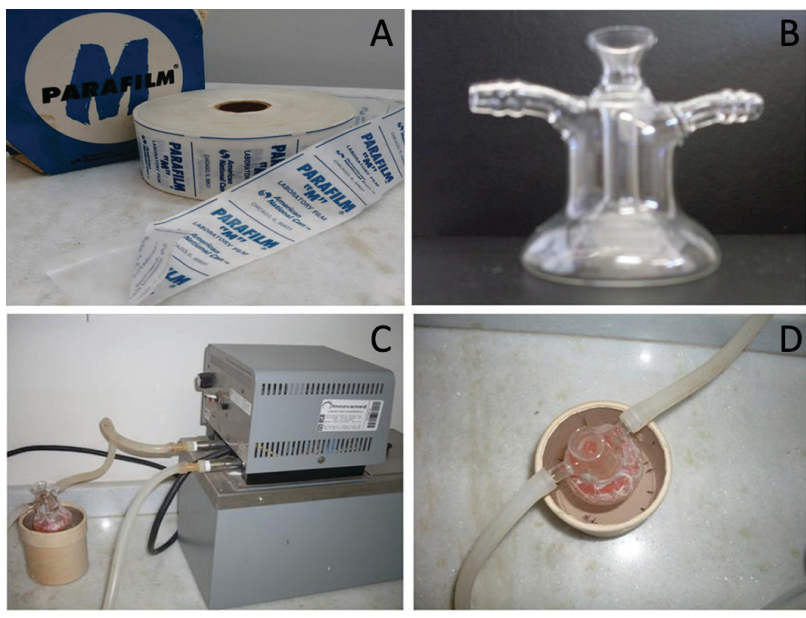

Figure 1 - Apparatus used for artificial feeding: A) Parafilm- ${ }^{\circledR}$ roll; B) Jacketed glass with conical bottom; C) Artificial feeding using circulating water bath to maintain the blood warm; D) Cage top view during artificial feeding of Culicidae
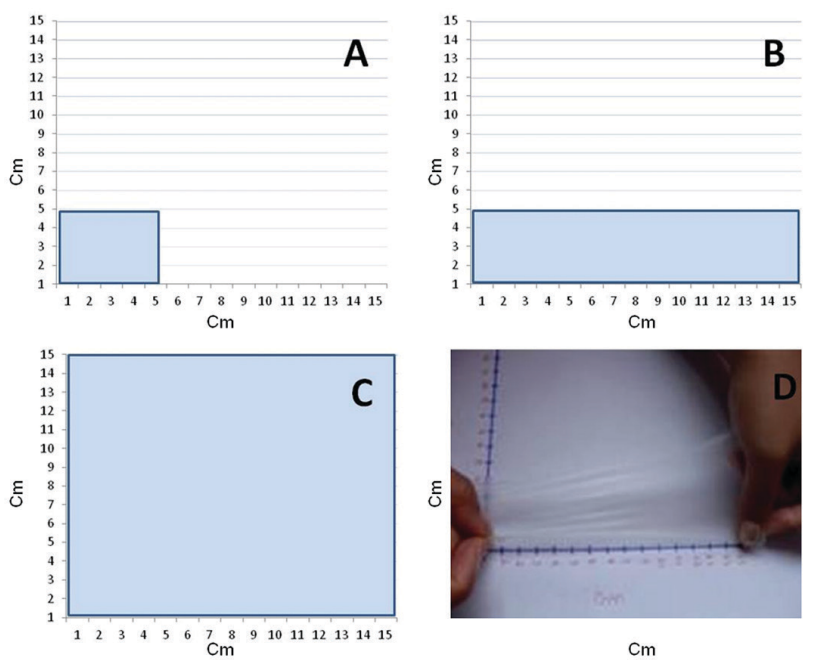

Figure 2 - Parafilm preparation scheme for artificial feeding: A) Parafilm before stretching measuring $5 \times 5 \mathrm{~cm}$; B) Initial procedure of the parafilm stretching process leading to the measurement of $5 \times 15 \mathrm{~cm}$; C) Final procedure of the parafilm stretching process in the second direction leading to the measurement of $15 \times 15 \mathrm{~cm}$; D) Display of the parafilm after the first stretching measuring $5 \times 15 \mathrm{~cm}$

the glass "jacket", thus transferring heat to the blood offered to the female insects.

For artificial blood feeding, females were transferred to "feeding cages", a cylindrical cardboard recipient measuring $9.5 \times 8.5 \mathrm{~cm}$ with a movable bottom and a mesh sealed cover. After the females transfer to these cages, the bottom was suspended at a distance of approximately three centimeters from the cover, thus bringing the mosquitoes closer to the blood source, facilitating the repast (Figure 3). Prior to artificial feeding, blood contained in a glass vial was homogenized by gentle inversion of the tube in order to avoid sedimentation of red blood cells. This ensured that
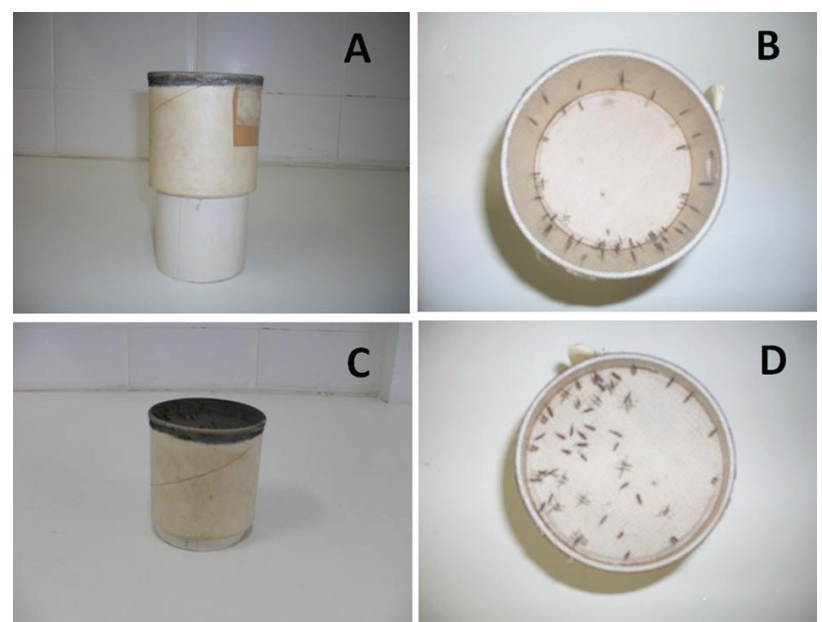

Figure 3 - Feeding cage with a movable bottom: A) External view of the feed cage with distended bottom; B) Inside view of the feed cage with distended bottom; C) External view of the feed cage with suspended bottom; D) Internal view of the feed cage with suspended bottom

the blood supplied during the short artificial feeding period was homogeneous.

For each mosquito species, four cages were used simultaneously in each artificial feeding process. Two cages were exposed to citrated blood and the other two cages were exposed to defibrinated blood from a specific animal (sheep or rabbit). At the same time, guinea pigs were offered to mosquito females contained in two cages for direct blood feeding (control). For both, direct guinea pig feeding and artificial feeding, the mosquitoes' exposure time was $30 \mathrm{~min}$. All blood-feeding procedures were performed in replicates of four on different days. Hence, a total of 2,000 females were tested per mosquito species.

\section{Quantification of blood ingested per female}

In order to quantify the volume of ingested blood in each blood source condition, three groups of 10 females per species were removed from the cages before the blood feeding procedure. These females were then weighted and discarded. Just after the blood feeding procedure, unfed females (those that did not present the abdomen dilated due to blood ingestion) were removed from the cages and eliminated. Later, three groups of 10 blood-fed females per species were removed from the cages, weighted and discarded. For the weighting procedure, in both conditions, females were retained during $30 \mathrm{~s}$ in an adapted lethal tube: $20 \mathrm{~mL}$ test tube containing cotton and paper soaked with $100 \%$ ethyl acetate. The weight of these mosquitoes was determined using an analytical balance (APX - 200, Denver Instrument). This procedure was performed for all species and blood source conditions evaluated. The remaining 
blood-fed females were transferred to breeding cages and were offered a $10 \%$ sugar solution.

\section{Quantification of Ae. aegypti eggs and larvae}

Three days after blood meal, 30 females from each blood source condition were individually transferred to Petri dishes ( $6 \mathrm{~cm}$ in diameter $\times 1.5 \mathrm{~cm}$ in height) adapted for posture. Each Petri dish was inverted and the cap bottom was coated with a filter paper moistened with $700 \mu \mathrm{L}$ of a solution containing non-chlorinated water mixed with breeding water (water taken from larvae raising bowls that stimulates eggs posture and hatching). This procedure was adapted from Valencia et al. ${ }^{21}$ Petri dishes containing a single female were placed in a stove type B.O.D., with a constant temperature of $26^{\circ} \mathrm{C}$ and humidity of $80 \%$. After $24 \mathrm{~h}, 300 \mu \mathrm{L}$ of nonchlorinated water were added to each Petri dish to ensure moisture. Forty-eight hours later, females were removed from Petri dishes and discarded. Petri dishes containing the moist filter papers with eggs were returned to the incubator. They were kept at $26{ }^{\circ} \mathrm{C}$ for approximately seven days for drying after counting the number of eggs per female. Later, $10 \mathrm{~mL}$ of breeding water were added in each Petri dish to stimulate eggs hatching. Petri dishes were maintained in a B.O.D., with a constant temperature of $26{ }^{\circ} \mathrm{C}$. After $48 \mathrm{~h}$, the number of larvae per Petri dish was counted. At the end of the procedure, the number of eggs and their viability were recorded for each female.

\section{Quantification of eggs and larvae of An. aquasalis}

Three days after the blood meal, three groups of 10 females were separated in cardboard cages $(16.5 \mathrm{~cm}$ in diameter by $17.5 \mathrm{~cm}$ in height). Later, black plastic cups $(6 \mathrm{~cm}$ in diameter $\mathrm{x} 4 \mathrm{~cm}$ in height) containing approximately $100 \mathrm{~mL}$ of breeding water were introduced into the cages for eggs collection. To prevent desiccation of the eggs, the inner walls of the black plastic cups were coated with filter paper, in contact with the water. After three days, the plastic cups were removed and the eggs of each group of ten females were counted and placed in appropriate plastic bowls for the daily monitoring of the egg hatching rate. Larvae number and eggs viability were monitored up to the first day after total eggs hatching or until the fifth day after eggs hydration.

\section{Quantification of eggs and larvae of Cx. quinquefasciatus}

Three days after the blood meal, three groups of 10 females were separated in colony cages. Later, two
$50 \mathrm{~mL}$ disposable plastic cups, containing approximately $45 \mathrm{~mL}$ of dechlorinated water, were introduced into each cage for eggs collection. After three days, the total number of eggs from each group of 10 females was recorded and the eggs were placed in appropriate plastic bowls for the daily monitoring of egg hatching rate. The larvae number and eggs viability were monitored up to the first day after the total eggs hatching or until the fifth day after the eggs count.

\section{Statistical analysis}

All statistical analyses were performed using GraphPadPrism version 6.0 for Windows (GraphPad Software, San Diego California USA, http://www.graphpad.com). One-way analysis of variance (ANOVA) followed by the Tukey test was used to determine whether there were any statistically significant differences $(\mathrm{p}<0.05)$ in the experiments of blood feeding, oviposition and egg hatching rate. Student's test was performed to compare the weight of unfed and fed females under different blood feeding conditions.

\section{RESULTS}

\section{Rate of females that performed blood feeding}

\section{Ae. aegypti}

The mean percentage of females fed directly on guinea pigs (96\%) did not differ significantly in relation to artificial feeding using citrated sheep blood (97\%), defibrinated sheep blood (95\%), citrated rabbit blood (98\%) and defibrinated rabbit blood (98\%). In addition, there was no significant difference in the mean percentage of fed females among all conditions of artificial blood feeding ( $p>0.05$ ) (Figure 4).

\section{Cx. quinquefasciatus}

The mean percentage of females directly fed on guinea pigs (67\%) was significantly higher than the mean percentage of females artificially fed through the parafilm membrane using citrated sheep blood (45\%), defibrinated sheep blood (37\%), citrated rabbit blood $(48 \%)$ and defibrinated rabbit blood (43\%). Considering the artificial feeding, the average percentage of females fed with defibrinated sheep blood was significantly lower than the average percentage of females fed with citrated rabbit blood ( $p<0.05$ ). There were no significant differences in the mean percentage of fed females when other blood types were offered through artificial feeding ( $p>0.05)$ (Figure 4).

\section{An. aquasalis}

The mean percentage of females fed directly on guinea pigs (72\%) was significantly lower than the mean 
A

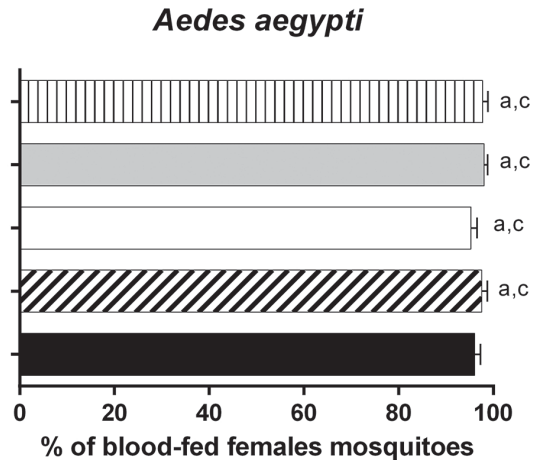

C

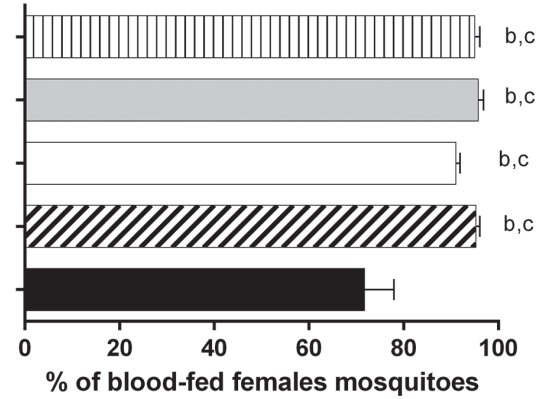

B

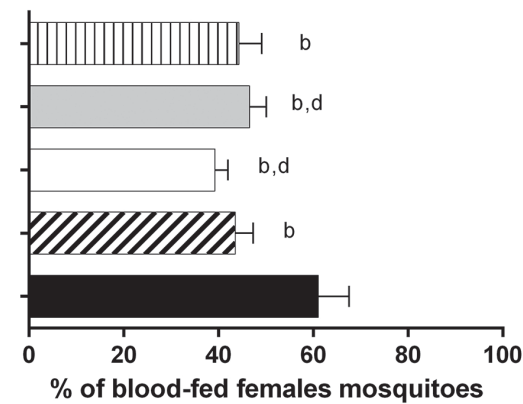

Figure 4 - Percentage of females artificially fed in the different evaluated conditions and in the direct feeding on guinea pig. A- Ae. aegypti, B- Cx. quinquefasciatus and C- An. aquasalis. Bars followed by the letter a represent no significant difference compared with guinea pig; bars followed by the letter b represent significant difference compared with guinea pig; bars followed by the letter $\mathrm{C}$ represent no significant difference among the other sources of blood in artificial feeding; bars followed by letter $\mathrm{d}$ represent significant difference among the other sources of blood in artificial feeding. One-way Anova corrected by Tukey test

percentage of females fed with all blood types offered through the artificial feeding apparatus: citrated sheep blood (95\%), defibrinated sheep blood (91\%), citrated rabbit blood (96\%) and defibrinated rabbit blood (95\%) (p $<0.05)$. There were no significant differences between the mean percentage of females artificially fed with the different types of blood ( $p>0.05$ ) (Figure 4).

\section{Amount of ingested blood}

The amount of ingested blood was measured considering the average weight of groups containing ten females before blood repast and the average weight of groups containing ten females after blood repast. Results for all species and blood sources are presented in Table 1, as well as the ratio between the weight of females after blood repast and the weight of unfed females.

Unfed females presented a significant difference in body weight compared with females fed with all the different blood sources (direct feeding and artificial feeding) in the three evaluated species $(\mathrm{p}<0.05)$ (Table 1$)$. For Ae. aegypti the body weight ratio of the fed females groups ranged from 2.1 to 3.1 times when compared to unfed females. The weight of females fed artificially with citrated rabbit blood and defibrinated sheep blood were significantly lower than the weight of females fed directly on guinea pig.

For Cx. Quinquefasciatus, the amount of blood ingested during artificial feeding for all conditions did not reach significant difference between the direct feeding in the guinea pig, or among different artificial feeding conditions ( $p>0.05$ ). The body weight ratio of fed females groups varied from 1.6 to 2.1 times when compared to non-fed females.

In An. aquasalis there was no significant difference between the direct feeding on guinea pig and the artificial feeding using citrated sheep blood, defibrinated sheep blood and defibrinated rabbit blood ( $p>0.05)$, but there was a significant difference between artificial feeding using citrated rabbit blood and the direct feeding on guinea pig $(\mathrm{p}<0.05)$. Despite this, no significant difference was found among the artificial feeding conditions evaluated ( $>0.05$ ). The body weight ratio of fed females groups varied from 1.6 to 2.4 times when compared to unfed females. 
Table 1 - Mean weight and ratio of ingested blood of Ae. aegypti, Cx. quinquefasciatus and An. Aquasalis females exposed to direct (guinea pig) or artificial (sheep and rabbit) blood feeding

\begin{tabular}{|c|c|c|c|}
\hline Species & Blood meals & Weight $\bar{X}(\mathrm{mg})$ & Ratio of ingested blood* \\
\hline \multirow{6}{*}{ Ae. aegypti } & Unfed & 17,2 & - \\
\hline & Live guinea pig & $53,9^{a}$ & 3,1 \\
\hline & Citrated sheep blood & $45,8^{a, c, d}$ & 2,7 \\
\hline & Defibrinated sheep blood & $37,0^{a, b, d}$ & 2,1 \\
\hline & Citrated rabbit blood & $37,4^{a, b, d}$ & 2,2 \\
\hline & Defibrinated rabbit blood & $40,2^{\mathrm{a}, \mathrm{c}, \mathrm{d}}$ & 2,3 \\
\hline \multirow{6}{*}{ Cx. quinquefasciatus } & Unfed & 17,2 & - \\
\hline & Live guinea pig & $35,7^{a}$ & 2,1 \\
\hline & Citrated sheep blood & $31,7^{\mathrm{a}, \mathrm{c}, \mathrm{d}}$ & 1,8 \\
\hline & Defibrinated sheep blood & $27,3^{\mathrm{a}, \mathrm{c}, \mathrm{d}}$ & 1,6 \\
\hline & Citrated rabbit blood & $33^{a, c, d}$ & 1,9 \\
\hline & Defibrinated rabbit blood & $30,0^{a, c, d}$ & 1,7 \\
\hline \multirow{6}{*}{ An. aquasalis } & Unfed & 14,2 & - \\
\hline & Live guinea pig & $33,6^{a}$ & 2,4 \\
\hline & Citrated sheep blood & $26,7^{\mathrm{a}, \mathrm{c}, \mathrm{d}}$ & 1,9 \\
\hline & Defibrinated sheep blood & $26,7^{\mathrm{a}, \mathrm{c}, \mathrm{d}}$ & 1,9 \\
\hline & Citrated rabbit blood & $22,8^{\mathrm{a}, \mathrm{b}, \mathrm{d}}$ & 1,6 \\
\hline & Defibrinated rabbit blood & $24,2^{\mathrm{a}, \mathrm{c}, \mathrm{d}}$ & 1,7 \\
\hline
\end{tabular}

${ }^{*}$ Ratio of ingested blood calculated by dividing the mean weight of groups of 10 fed mosquitoes (under different feeding conditions) by the mean weight of groups of 10 unfed mosquitoes. Student t test analysis ${ }^{a}=$ Significant difference compared with the weight of unfed females of the same species; ${ }^{b}=$ Significant difference compared with the guinea pig; ${ }^{c}=$ No significant difference when compared with direct feeding on guinea pig; ${ }^{d}=$ No significant difference when compared with another artificial feeding condition

\section{Number of eggs laid per female}

In Ae. aegypti, the mean number of eggs laid per female fed on guinea pig was 83 (Figure 5A). This number did not differ significantly from the ones obtained from other blood sources evaluated in artificial feeding ( $p>0.05)$. The mean number of eggs from females artificially fed with defibrinated sheep blood presented a difference significantly lower than the mean number of eggs of females fed artificially with citrated rabbit blood $(\mathrm{p}<0.05)$. The mean number of eggs per female in the other sources of blood used in artificial feeding did not present significant differences among them ( $\mathrm{p}>0.05)$.

For $C x$. quinquefasciatus, there was a significant difference in oviposition among all artificial feeding conditions evaluated and direct feeding on guinea pigs, as well as among the different artificial feeding conditions $(\mathrm{p}<0.05)$. In the artificial feeding, the mean number of eggs produced in the feeding with defibrinated sheep blood was significantly lower than all other blood sources evaluated. Among the blood sources of artificial feeding, citrated rabbit blood presented the best result with an average of 44 eggs compared to citrated sheep blood (mean of 39 eggs), defibrinated sheep blood (mean of $30 \mathrm{eggs}$ ) and defibrinated rabbit blood (mean of 36 eggs). The mean of guinea pig direct feeding was slightly higher (55 eggs) (Figure 5B).

For An. Aquasalis, an average of 76 eggs were laid per female fed directly on guinea pig. This number significantly differed from all blood sources evaluated in artificial feeding (Figure 5C). The mean number of eggs from females artificially fed with citrated rabbit blood was significantly higher than the number of eggs produced in artificial feeding using citrated sheep blood and defibrinated sheep blood.

\section{Egg hatching rate}

In the artificial blood feeding, the three studied species showed significant differences in egg hatching rate among the different blood sources and preservation ways (citrated and defibrinated sheep blood, citrated and defibrinated rabbit blood). In addition, there was also a significant difference between the hatching rate of females fed through artificial feeding compared to females fed directly on guinea 
A

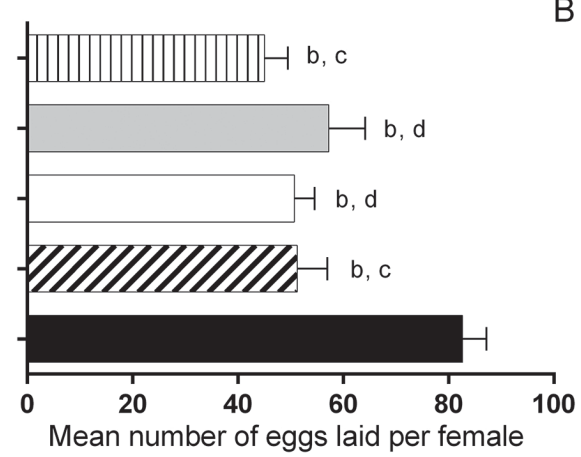

C

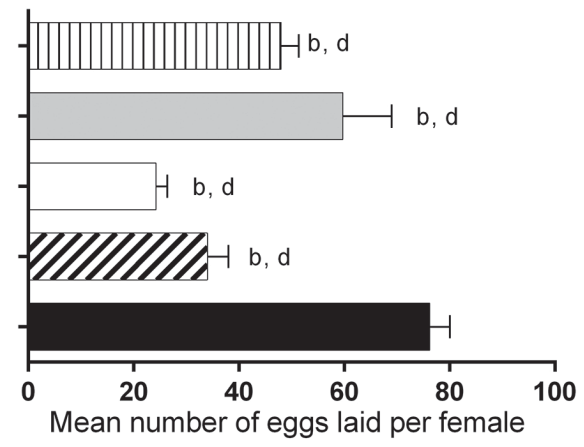

Culex quinquefasciatus

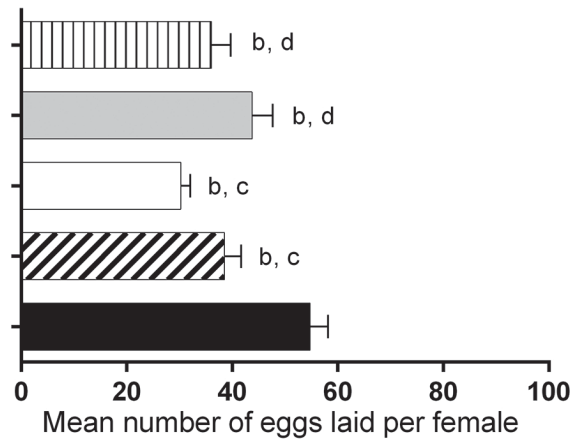

Figure 5 - Mean number of eggs laid per female from artificial feeding under the different evaluated conditions and from direct feeding in guinea pig. A- Ae. aegypti, B- Cx. quinquefasciatus and C- An. aquasalis. Bars followed by the letter b represent significant difference with respect to the guinea pig; bars followed by the letter $\mathrm{c}$ represent no significant difference between the other sources of blood in artificial feeding; bars followed by the letter d represent significant difference between the other sources of blood in artificial feeding. One-way Anova correction by Tukey test

pigs in all three genera $(\mathrm{p}<0.05)$, as shown in Figures 6A, $\mathrm{B}$ and $\mathrm{C}$.

In Ae. aegypti, the egg hatching rate in artificially feeding conditions ranged from $54 \%$ (females fed with defibrinated rabbit blood) to $69 \%$ (females fed with citrated rabbit blood). The egg hatching rate for direct feeding on guinea pig was $85 \%$.

In $C x$. quinquefasciatus, the egg hatching rate in artificially feeding conditions ranged from $45 \%$ (females fed with defibrinated sheep blood) to $69 \%$ (females fed with citrated rabbit blood). The egg hatching rate for direct feeding on guinea pig was $89 \%$.

In An. aquasalis, the egg hatching rate in artificially feeding conditions ranged from $51 \%$ (female fed with defibrinated sheep blood) to $69 \%$ (females fed with citrated rabbit blood). The egg hatching rate for direct feeding on guinea pig was $79 \%$.

Direct guinea pig feeding was slightly superior compared with all artificial feeding conditions. Among the artificial feeding conditions, feeding with citrated rabbit blood resulted in a higher egg hatching rate in all evaluated mosquito genera.

\section{DISCUSSION}

The creation of mosquitoes vector of diseases in the laboratory is necessary for conducting research to better understand the biology of these organisms and the pathogens they transmit. In order to maintain Culicidae colonies in the laboratory, it is necessary to find a proper blood supply for the female feeding process and consequent egg production. Direct blood feeding on anesthetized guinea pigs requires the maintenance of a bioterium in the laboratory associated with a great financial and specialized work expense. The artificial blood feeding of mosquito females arises as a strong tendency since the use of blood taken from mammals implies in minimization of the animal pain and discomfort. It also reduces costs associated with the maintenance of a bioterium in the laboratory.

In this work, we used Parafilm-M ${ }^{\circledast}$ membrane to seal glass flasks containing mammalian blood. Historically, wide varieties of membranes have been used during the process of blood artificial feeding of hematophagous insects. Some studies indicated that membranes of animal origin are superior than those of vegetable or synthetic origins ${ }^{8,22}$. 
Aedes aegypti

A

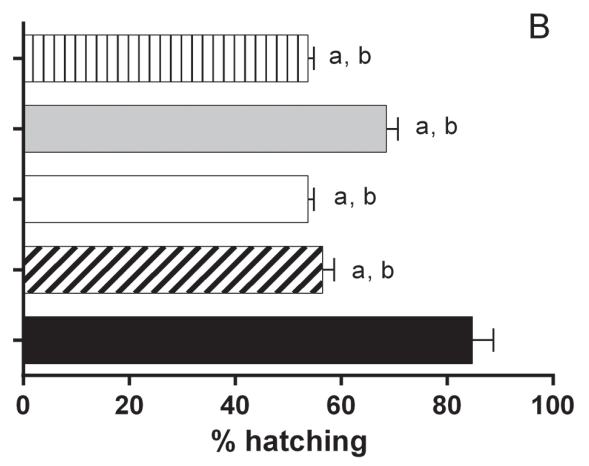

Anopheles aquasalis

C

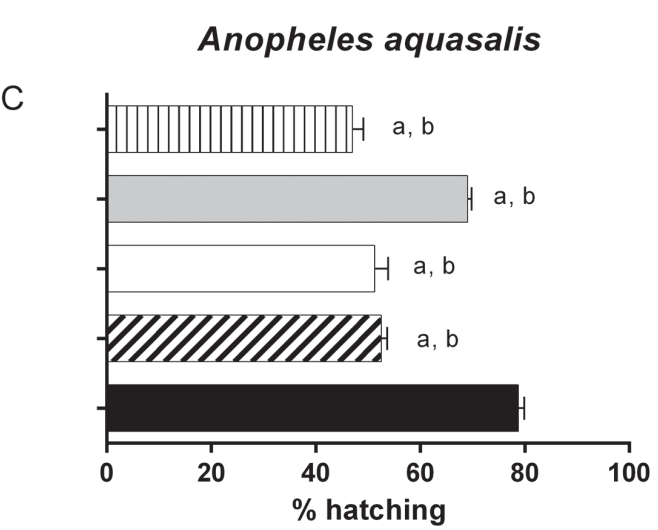

Culex quiquefasciatus

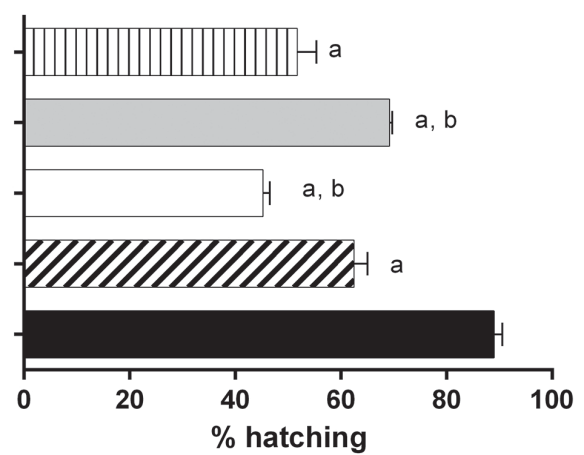

Figure 6 - Average percentage of eggs hatching from artificially fed females under the different evaluated conditions and from females directly fed on guinea pig. A- Ae. aegypti, B- Cx. quinquefasciatus and C- An. aquasalis. Bars followed by the letter a represent significant difference with respect to the guinea pig. Bars followed by the letter b represent no significant difference between them. One-way Anova correction by Tukey test

Carvalho ${ }^{23}$ used rubber membranes to artificially feed hematophagous insects offering defibrinated or citrated blood of bovine, human or ovine, at a temperature of $37^{\circ} \mathrm{C}$. The author concluded that hematophagous insects adapted well to the rubber membrane, especially the triatomines. Greenberg ${ }^{7}$ observed that membrane of cellophane paper was not effective in blood artificial feeding of Ae. aegypti. This author also showed that natural membranes from animal skin are good for blood artificial feeding, but are not easy to prepare, especially when a large number is required. Pina and Fonseca ${ }^{2}$ used silicone membrane to feed Ae. aegypti with bovine blood and obtained 30\% of engorged females. Rutledge et al. ${ }^{8}$ considered Parafilm-M ${ }^{\otimes}$ as a satisfactory membrane for Anopheles blood feeding. Tseng ${ }^{24}$ obtained $53 \%$ of females ingurgitated when feeding Ae. aegypti with sheep citrated blood using Parafilm- $\mathrm{M}^{\circledR}$ membrane. Moutailler et al. ${ }^{25}$, studying the Rift Valley fever virus transmission, artificially fed $C x$. quinquefasciatus using Parafilm- $\mathrm{M}^{\circledast}$ membrane, obtaining only $1 \%$ of engorged females. However, Nasirian and Ladonni ${ }^{26}$ tested artificial feeding in Anopheles stephensi (Liston, 1901) using human blood through Parafilm- $\mathbf{M}^{\circledast}$ membrane. The authors obtained a maximum engorgement rate of $90.9 \%$.
Costa-da-Silva et al. ${ }^{14}$ fed Ae. aegypti through Parafilm-M ${ }^{\circledR}$ membrane using an apparatus called "Glytube" which consisted of a conical plastic tube containing $40 \mathrm{~mL}$ of warm $100 \%$ glycerol for heating the blood. The tube screw cap was perforated and sealed with Parafilm- $\mathbf{M}^{\circledast}$. After the glycerol was added, the tube was sealed with a Parafilm-M ${ }^{\circledR}$ membrane. The modified cap was used to close the tube creating a vacuum between the two Parafilm-M ${ }^{\otimes}$ membranes where the blood was retained. This feeding method reached the rate of $51.3 \%$ fed females. The observed differences in the efficiency of Parafilm-M ${ }^{\circledast}$ membrane may be associated with its preparation. The membrane must be relatively thin, so that mosquitoes can perforate it easily, but sturdy enough to avoid blood leakage. The standardization of Parafilm- $\mathrm{M}^{\circledR}$ membrane distension may have been highly relevant to the success of artificial blood feeding in our evaluations. In addition, the use of retractable bottom cages may have contributed to this improvement in blood feeding as the mosquitoes were confined is a restrict space closer to the blood source. The Parafilm- $\mathrm{M}^{\circledR}$ membrane, with the aid of the retractable bottom cage, was effective for blood artificial feeding in all species tested in this study. High feeding percentage was obtained for Ae. aegypti (98\%) 
and An. aquasalis (96\%). For Cx. quinquefasciatus, the percentage of feeding was not so high $(48 \%)$, but it was good enough to allow the maintenance of this species colonies in laboratories.

Several factors can affect Culicidae blood feeding, such as tactile, visual, olfactory stimuli, feeding surface temperature, blood temperature, among others ${ }^{27,28}$. These variables are optimally present in direct feeding on live animals and, for this reason, a lower percentage of culicides artificially fed was expected when compared to direct feeding. Regarding the number of blood fed Ae. aegypti females, our evaluations pointed to statistically equal results between guinea pig direct feeding and artificial feeding. Surprisingly, in An. aquasalis, artificial blood feeding had a higher percentage of fed females especially when using citrated rabbit blood (96\%) when compared to direct feeding on guinea pig $(72 \%)$. This indicates a potential increase in the number of specimens in colonies maintained with artificial feeding.

In $C x$. quinquefasciatus artificial feeding was not as efficient as it was in the other two studied species. Among the artificial feeding conditions, feeding with citrated rabbit blood was the one that presented the highest percentage of fed females (48\%), a result that was $19 \%$ lower than the direct feeding on guinea pig $(67 \%)$. Novak et al. ${ }^{29}$, comparing different types of membranes for artificial feeding of mosquitoes, also observed that Cx. quinquefasciatus females are more reluctant to feed through artificial membranes than directly on live animal. Nevertheless, the percentages obtained in our experiments were much higher than those observed in the literature ${ }^{22-26}$. In this study and in the cited reports $C x$. quinquefasciatus females were fed in dark conditions, which is usually preferable for this species. Therefore, feeding results were not affected by the time of feeding.

Mosquitoes of all studied genera increased their weight by an average of 1.61 to 2.37 times when artificially fed and 2.2 to 3.1 times when directly fed on guinea pig, which corroborates the findings of Clements ${ }^{30}$ who noted that a female mosquito is able to ingest more than three times its own weight in blood in a short period. The lowest weight averages observed in the artificial feeding suggests that without the live animal attractive components the mosquito females spend less time feeding when in contact with the artificial membrane.

For the three genera studied, the mean number of eggs laid per female was higher when mosquitoes were fed direct on guinea pigs (Ae. aegypti 83 eggs, Cx. quiquefasciatus 55 eggs, and An. aquasalis 76 eggs) (Figure 5). Among the artificial feeding conditions the highest number of eggs laid per female was observed when mosquitoes were fed with citrated rabbit blood (Ae. aegypti 57 eggs,
Cx. quinquefasciatus 44 eggs, and An. aquasalis 60 eggs). Compared to direct feeding on guinea pigs, the number of eggs laid per female was lower in artificial feeding using citrated rabbit blood. Despite this, the number of eggs obtained after artificial feeding was high enough to guarantee the colony perpetuation.

Direct feeding on guinea pig resulted in high percentages of hatched eggs for the three genera studied (Figure 6). Among the artificial feeding conditions, the highest percentage of hatched eggs was observed when citrated rabbit blood was offered. The results suggest that the anticoagulant procedures not only influence negatively the number of eggs laid per female but also the viability of those eggs. However, the reduction of these life trait characteristics is less severe when citrated rabbit blood is offered, indicating this artificial condition as the best to replace direct feeding on mammals.

Some authors have already shown that defibrinated blood is well accepted by several groups of hematophagous insects. Rodhain et al. ${ }^{31}$ showed that individuals of the species Glossina palpalis were successfully fed with defibrinated sheep blood through mice skin membrane. MacDonald and $\operatorname{Scott}^{32}$ were successful in feeding Ornithonyssus bacoti mites with defibrinated blood from several species of mammals through the skin membrane of chicks and mice. The present study presented different results. In all evaluated parameters rabbit or sheep defibrinated blood presented inferior performance when compared to citrated blood or direct feeding in the guinea pig, except for artificial feeding with citrated rabbit blood in An. aquasalis, where females fed a smaller amount of blood. Nevertheless, the oviposition and hatch rate of eggs of An. aquasalis artificially fed using citrated rabbit blood were higher than the number of eggs and the hatch rate of eggs achieved using other artificial feeding conditions.

Except for the above mentioned episode, in our evaluations we observed that both, the number of eggs and the hatch rate of eggs of mosquito females artificially fed with sheep blood were lower compared to other blood sources. The fall was even greater when the blood was conserved by defibrillation. Phasomkusolsil et al. ${ }^{15}$, while performing artificial blood feeding experiments in Culicidae, observed that sheep blood negatively affected the number of laid eggs and the hatch rate of eggs of Ae. aegypti and some Anopheles species. It is possible that this has happened in our experiments as well. Experiments using citrated rabbit blood presented results most similar to the results obtained when females were fed directly on guineapigs, regardless of the genera of the evaluated mosquito (Culex, Anopheles and Aedes). Artificial feeding using citrated rabbit blood also showed superior performance in 
both, the number of laid eggs and the hatch rate of eggs, when compared to artificial feeding using defibrinated blood (rabbit and sheep) and citrated sheep blood.

These results are in conformity with the observation made by Woke ${ }^{33}$ and Pina and Fonseca ${ }^{2}$ that compared the effect of different treatments on Ae. aegypti oviposition and observed that the decalcification of the blood resulting from addition of anticoagulant sodium citrate did not decrease the number of eggs laid or the hatch rate of eggs in this species.

Among the blood types and conservation conditions evaluated, citrated or defibrinated sheep blood have not shown good results to justify their use in the maintenance of Culicidae colonies. However, rabbit blood maintained a recovery rate always very close to the control (direct feeding on guinea pigs), especially when citrated, without loss in egg production and larvae hatching.

Blood from different animals usually contains different components of proteins and other chemicals. It has been established that mosquito meals must contain proteins for egg development ${ }^{34}$. Amino acids are important for vitellogenesis ${ }^{35}$ and several studies have shown the importance of essential amino acids for egg production ${ }^{36-39}$. Kogan ${ }^{34}$ has mentioned that bovine blood had to be supplemented with isoleucine for Ae. aegypti feeding as the whole bovine blood was low in isoleucine. This indicates that amino acid composition is essential to guarantee successful egg production. We are not aware of any study indicating amino acid composition in the whole blood of sheep, rabbit and guinea pig. Therefore, it is not possible to indicate at this point if the differences in efficiency of blood feeding found in this study were due to amino acids composition of each blood type or if they were due to other factors. Future studies are needed to clarify if all components of the mammalian blood involved in vitellogenesis process of mosquitoes and egg production are present in the blood of sheep, rabbit and guinea pig.

We conclude that it is possible to replace Culicidae direct blood feeding on guinea pigs by artificial feeding in the laboratory. The citrated rabbit blood was shown to be the best option among those evaluated in this study.

\section{ACKNOWLEDGMENTS}

The authors are thankful to Gilberto Couto Alcantara for his technical contribution on the maintenance of mosquito colony.

\section{CONFLICT OF INTERESTS}

The authors have declared that no competing interests exist.

\section{AUTHORS' CONTRIBUTIONS}

LSD: Experimental design, test development, data interpretation, statistical analysis, text writing, approval to publish the manuscript; LGSRB: data interpretation, statistical analysis, text writing, approval to publish the manuscript; JBPL: Experimental design, data interpretation, text writing, approval to publish the manuscript.

\section{FUNDING}

Fundação Oswaldo Cruz.

\section{REFERENCES}

1. Forattini OP. Culicidologia médica. São Paulo: EDUSP, 19962002.

2. Pina IG, Fonseca AH. Comportamento de Aedes aegypti L., 1762 (Diptera: Culicidae) alimentados artificialmente com sangue de diferentes espécies de doadores. Rev Patol Trop. 1999;28:6471 .

3. Gubler DJ. Dengue and dengue hemorrhagic fever. Clin Microbiol Rev. 1998;11:480-96.

4. Pimenta LG, Silva AL. Ética e experimentação animal. Acta Cir Bras. 2001;16:255-60.

5. Andrade A, Pinto SC, Oliveira RS, organizadores. Animais de laboratório: criação e experimentação. Rio de Janeiro: FIOCRUZ; 2002.

6. Deng L, Koou SY, Png AB, Ng LC, Lam-Phua SG. A novel mosquito feeding system for routine blood-feeding of Aedes aegypti and Aedes albopictus. Trop Biomed. 2012; 29:169-74.

7. Greenberg J. A method for artificially feeding mosquitoes. Mosq News. 1949;9:48-50.

8. Rutledge LC, Ward RA, Gould DJ. Studies on the feeding response of mosquitoes to nutritive solutions in a new membrane feeder. Mosq News. 1964;24:407-19.

9. Pipkin AG, Connor TJ. A temperature-controlled feeding apparatus for hematophagous arthropods. J Med Entomol. 1968;5:507-9.

10. Bailey DL, Dame DA, Munroe WL, Thomas JA. Colony maintenance of Anopheles albimanus Wiedemann by feeding preserved blood through natural membrane. Mosq News. 1978;38:403-8.

11. Wirtz RA, Rutledge LC. Reconstituted collagen sausage casings for the blood feeding of mosquitoes. Mosq News. 1980;40:2878.

12. Hagen HE, Grunewald J. Routine blood-feeding of Aedes aegypti via a new membrane. J Am Mosq Control Assoc. 1990;6:535-6.

13. Kasap H, Alptekin D, Kasap M, Güzel AI, Lüleyap U. Artificial blood feeding of Anopheles sacharovi on a membrane apparatus. J Am Mosq Control Assoc. 2003;19:367-70. 
14. Costa-da-Silva AL, Navarrete FR, Salvador FS, Karina-Costa M, Ioshino RS, Azevedo DS, et al. Glytube: a conical tube and parafilm M-based method as a simplified device to artificially blood-feed the dengue vector mosquito, Aedes aegypti. PLoS One. 2013;8:e53816.

15. Phasomkusolsil S, Tawong J, Monkanna N, Pantuwatana K, Damdangdee N, Khongtak W, et al. Maintenance of mosquito vectors: effects of blood source on feeding, survival, fecundity, and egg hatching rates. J Vector Ecol. 2013;38:38-45.

16. Luo YP. A novel multiple membrane blood-feeding system for investigating and maintaining Aedes aegypti and Aedes albopictus mosquitoes. J Vector Ecol. 2014;39:271-7.

17. Finlayson C, Saingamsook J, Somboon P. A simple and affordable membrane-feeding method for Aedes aegpyti and Anopheles minimus (Diptera: Culicidae). Acta Trop. 2015;152:245-51.

18. Gunathilaka N, Ranathunge T, Udayanga L, Abeyewickreme W. Efficacy of blood sources and artificial blood feeding methods in rearing of Aedes aegypti (Diptera: Culicidae) for sterile insect technique and incompatible insect technique approaches in Sri Lanka. Biomed Res Int. 2017;2017:3196924.

19. Remfry J. Ethical aspects of animal experimentation. In: Tuffery AA, editor. Laboratory animals: an introduction for new experimenters. New York: John Wiley \& Sons; 1987. p.5-19.

20. Gerberg EJ. Manual for mosquito rearing and experimental techniques. $5^{\text {th }}$ ed. Lake Charles: American Mosquito Control Association; 1970.

21. Valencia MD, Miller LH, Mazur P. Permeability of intact and dechorionated eggs of the Anopheles mosquito to water vapor and liquid water: a comparison with Drosophila. Cryobiology. 1996;33:142-8

22. Lyski ZL, Saredy JJ, Ciano KA, Stem J, Bowers DF. Blood feeding position increases success of recalcitrant mosquitoes. Vector Borne Zoonotic Dis. 2011;11:1165-71.

23. Carvalho G. Método indireto para alimentação de insetos hematófagos. Rev Bras Biol. 1961;21:193-6.

24. Tseng M. A simple parafilm M-based method for blood-feeding Aedes aegypti and Aedes albopictus (Diptera: Culicidae). J Med Entomol. 2003;40:588-9.

25. Moutailler S, Bouloy M, Failloux AB. Short report: efficient oral infection of Culex pipiens quinquefasciatus by Rift Valley fever virus using a cotton stick support. Am J Trop Med Hyg. 2007;76:827-9.
26. Nasirian H, Ladonni H. Artificial blood feeding of Anopheles stephensi on a membrane apparatus with human whole blood. J Am Mosq Control Assoc. 2006;22:54-6.

27. Galun R. Feeding stimuli and artificial feeding. Bull World Health Organ. 1967;36:590-3.

28. Friend WG, Smith JJ. An apparatus for exchanging diets rapidly during artificial feeding of sucking insects. Can Entomol. 1977;109:15-20.

29. Novak MG, Berry WJ, Rowley WA. Comparison of four membranes for artificially blood feeding mosquitoes. J Am Mosq Control Assoc. 1991;7:327-9.

30. Clements AN. The biology of mosquitoes: volume 2: sensory reception and behaviour. Wallingford: CABI; 1999.

31. Rodhain J, Pons C, Vandenbranden J, Bequaert J. Contribution towards the transmission mechanism of trypanosomes by glossines. Arch Schiffs Tropen-Hyg. 1912;16:732-9.

32. Macdonald EM, Scott JA. Methods for feeding tropical rat mites on blood and other fluids through a membrane. Exp Parasitol. 1952;1:283-90.

33. Woke PA. Effects of various blood fractions on egg production of Aedes aegypti Linn. Am J Epidemiol. 1937;25:372-80.

34. Kogan PH. Substitute blood meal for investigating and maintaining Aedes aegypti (Diptera: Culicidae). J Med Entomol. 1990;27:709-12.

35. Gonzales KK, Hansen IA. Artificial diets for mosquitoes. Int J Environ Res Public Health. 2016;13:1267.

36. Uchida K, Oda T, Matsuoka H, Moribayashi A, Ohmori D, Eshita Y, et al. Induction of oogenesis in mosquitoes (Diptera: Culicidae) by infusion of the hemocoel with amino acids. $J$ Med Entomol. 2001;38:572-5.

37. Attardo GM, Hansen IA, Shiao SH, Raikhel AS. Identification of two cationic amino acid transporters required for nutritional signaling during mosquito reproduction. J Exp Biol. 2006;209:3071-8

38. Dimond JB, Lea AO, Brooks RF, DeLong DM. A preliminary note on some nutritional requirements for reproduction in female Aedes aegypti. Ohio J Sci. 1955;55:209-11.

39. Lea AO, Dimond JB, DeLong DM. Role of diet in egg development by mosquitoes (Aedes aegypti). Science. 1956;123:890-1. 